\section{(2) OPEN ACCESS}

\title{
Comorbidity and bystander cardiopulmonary resuscitation in out-of-hospital cardiac arrest
}

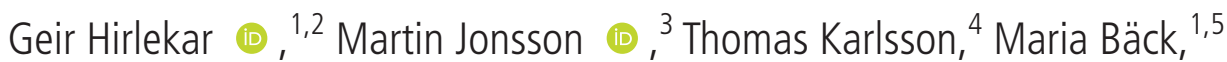 \\ Araz Rawshani, ${ }^{1}$ Jacob Hollenberg, ${ }^{3}$ Per Albertsson, ${ }^{1,2}$ Johan Herlitz ${ }^{6}$
}

\begin{abstract}
- Additional material is published online only. To view please visit the journal online (http://dx.doi.org/10.1136/ heartjnl-2019-315954).

'Department of Molecular and Clinical Medicine, Institute of Medicine, Sahlgrenska Academy, Goteborg, Sweden

2Department of Cardiology, Sahlgrenska University Hospital, Goteborg, Sweden

${ }^{3}$ Department of Medicine, Center for Resuscitation Science, Karolinska Institutet, Stockholm, Sweden

${ }^{4}$ Biostatistics, School of Public Health and Community Medicine, Institute of Medicine, Sahlgrenska Academy, Gothenburg, Sweden ${ }^{5}$ Department of Occupational Therapy and Physiotherapy, Sahlgrenska University Hospital, Gothenburg, Sweden

${ }^{6}$ Center for Pre-Hospital Research, University of Borås, Borås, Sweden
\end{abstract}

\section{Correspondence to} Geir Hirlekar, Department of Molecular and Clinical Medicine, Institute of Medicine, Sahlgrenska Academy, Goteborg 413 90, Sweden; geir.hirlekar@vgregion.se

Received 15 September 2019 Revised 7 December 2019 Accepted 13 December 2019 Published Online First 23 January 2020

\section{Check for updates}

(C) Author(s) (or their employer(s)) 2020. Re-use permitted under CC BY-NC. No commercial re-use. See rights and permissions. Published by BMJ.

To cite: Hirlekar $\mathrm{G}$ Jonsson M, Karlsson T, et al. Heart 2020;106:1087-1093.

\section{ABSTRACT}

Objective Cardiopulmonary resuscitation (CPR) performed before the arrival of emergency medical services (EMS) is associated with increased survival after out-of-hospital cardiac arrest (OHCA). The aim of this study was to determine whether patients who receive bystander CPR have a different comorbidity compared with patients who do not, and to determine the association between bystander CPR and 30-day survival when adjusting for such a possible difference.

Methods Patients with witnessed OHCA in the Swedish Registry for Cardiopulmonary Resuscitation between 2011 and 2015 were included, and merged with the National Patient Registry. The Charlson Comorbidity Index (CCI) was used to measure comorbidity. Multiple logistic regression was used to examine the effect of $\mathrm{CCl}$ on the association between bystander CPR and outcome. Results In total, 11955 patients with OHCA were included, $71 \%$ of whom received bystander CPR. Patients who received bystander CPR had somewhat lower comorbidity $(\mathrm{CCl})$ than those who did not (mean \pm SD: $2.2 \pm 2.3$ vs $2.5 \pm 2.4 ; p<0.0001)$. However, this difference in comorbidity had no influence on the association between bystander CPR and 30-day survival in a multivariable model including other possible confounders (OR $2.34(95 \% \mathrm{Cl} 2.01$ to 2.74) without adjustment for $\mathrm{CCl}$ and OR 2.32 (95\% Cl 1.98 to 2.71) with adjustment for $\mathrm{CCl}$ ).

Conclusion Patients who undergo CPR before the arrival of EMS have a somewhat lower degree of comorbidity than those who do not. Taking this difference into account, bystander CPR is still associated with a marked increase in 30-day survival after OHCA.

\section{INTRODUCTION}

Out-of-hospital cardiac arrest (OHCA) affects more than 350000 people in Europe annually, and people who suffer from OHCA have a low chance of survival. ${ }^{12}$ Survival from OHCA depends on the effectiveness of the chain of survival, where each link in the chain is important. ${ }^{3}$ Studies have shown that when cardiopulmonary resuscitation (CPR) is started before the arrival of emergency medical services (EMS), the chance of survival increases. $^{4-7}$ The survival effect of bystander CPR may be to prolong the duration of and thereby the shockable phase of ventricular fibrillation. ${ }^{89}$ One often neglected factor in patients who suffer from OHCA is previous comorbidities. ${ }^{10}$ In the periarrest phase there is often no time for the rescue team to obtain reliable information about the patient's clinical history. This has been unfortunate, since even 25 years ago it was argued in terms like 'one could just hope that being found in asystole and not receiving bystander CPR is not explained by suffering from a terminal disease' ${ }^{7}$ In theory, such a finding may influence the observed association between bystander CPR and survival. In the discussions about the association between bystander CPR and survival after OHCA, this dilemma has more or less been neglected. Studies have shown conflicting results regarding the association between comorbidity and survival. ${ }^{11} 12$ We recently reported that increasing comorbidity was associated with a decreased chance of 30-day survival after OHCA. ${ }^{13}$

In the present study, we studied patients who suffered a witnessed OHCA, in order to (1) determine whether those who receive CPR before the arrival of EMS exhibit different comorbidity features compared with patients who do not receive such treatment, and (2) determine the association between bystander CPR and 30-day survival when adjusting for such possible differences in comorbidities.

\section{METHODS}

\section{Setting}

Sweden has a population of 10 million, with a land area of more than $450000 \mathrm{~km}^{2} .{ }^{14}$ In cases of OHCA, all EMS systems have a two-tier response with basic life support as the first tier and advanced life support as the second tier. In addition to the ordinary EMS, some counties send out firefighters and/or police officers.

\section{Data sources}

The Swedish Registry for Cardiopulmonary Resuscitation (SRCR) is a national quality register which was initiated in 1990 and receives support from the Swedish Association of Local Authorities and Regions. More than $90 \%$ of all individuals who have suffered an OHCA in Sweden and in whom CPR was attempted by a bystander or EMS are reported to the registry. Thus, inclusion criteria for the registry are that CPR has been started either by health professionals in EMS or before the arrival of EMS by a bystander or by other dispatched units (firefighters and/or police officers). All EMS in Sweden report cases of OHCA to the registry prospectively using the Utstein-based template. ${ }^{15}$ The SRCR has been described elsewhere. ${ }^{16}$

The National Patient Registry (NPR) is run by the Swedish National Board of Health and Welfare. 
The coverage has been nationwide since 1987. The NPR has data on diagnoses and surgical procedure codes from hospitals and specialist clinics. An evaluation of the NPR has shown that $85 \%-95 \%$ of all diagnoses are valid. ${ }^{17}$ Since 2001 , the registry has also included outpatient visits from both private and public healthcare providers, but primary care is not covered by the NPR. All admissions (both inpatient and outpatient) are reported to the registry with International Classification of Diseases (ICD)-10 codes. $^{17}$

\section{Study design}

We retrospectively analysed all cases of witnessed OHCA in patients who were $\geq 18$ years of age from 2011 to 2015 in SRCR, and merged the data with comorbidity data from the NPR. Individuals with multiple OHCAs during the study period were only included once (the first occasion). Patients without a personal identification number (ie, with an unknown ID or nonresidents) were excluded, as were unwitnessed cases and cases that were witnessed only by the EMS crew. This research was done without patient involvement because of the registry-based design.

\section{Definitions}

We estimated comorbidity with the Charlson Comorbidity Index $(\mathrm{CCI})^{18}$ using ICD-10 diagnoses from the NPR registered 5 years before the OHCA. The use of ICD-10 diagnosis for determination of CCI has previously been reported. ${ }^{19}$ Bystander CPR was defined as any CPR before arrival of EMS started by a witness (a bystander) or other dispatched units (firefighters and police) before the arrival of EMS. ${ }^{15}$

\section{Outcome measures}

The primary outcome was 30-day survival. The secondary outcome was any return of spontaneous circulation (ROSC) and ROSC at hospital admission.

\section{Statistical analysis}

Baseline characteristics are presented as number (percentage) for proportions and median (10th, 90th percentiles) for continuous variables. Due to the large number of subjects in our study, we used the (absolute) standardised difference to assess the balance of baseline characteristics between the two groups (table 1). ${ }^{20}$ This measure is, in contrast to $\mathrm{p}$ values and hypothesis testing, independent of sample size and thus avoids detecting differences that are clinically meaningless. Values of at least 0.10 were considered to indicate a clinically relevant difference.

For the comorbid conditions constituting the CCI, as well as the CCI itself, though, we also presented-in addition to the standardised difference $-p$ values, since one of the aims of the study was to compare comorbidity between the two groups. Fisher's exact test and Mann-Whitney U test were used for these comparisons.

Fisher's exact test was also used for the unadjusted comparison of outcomes.

For calculation of ORs with corresponding CIs regarding outcomes, both in univariable (unadjusted) and multivariable (adjusted) analyses, logistic regression was used. Baseline factors used as covariates in the adjusted analysis were age, sex, location and aetiology of the cardiac arrest and time from call for EMS to arrival of EMS at the scene(). We did not primarily adjust for initial rhythm since this is believed to be an effect of bystander CPR (ie, prolonged time in shockable

Table 1 Baseline characteristics of the patients in relation to whether bystander CPR was performed before the arrival of EMS or not.

\begin{tabular}{|c|c|c|c|c|}
\hline & \multicolumn{3}{|c|}{ Bystander CPR } & \multirow[b]{2}{*}{ Standardised difference } \\
\hline & $\begin{array}{l}\text { All patients } \\
(n=11955)\end{array}$ & $\begin{array}{l}\text { Yes } \\
(n=8510)\end{array}$ & $\begin{array}{l}\text { No } \\
(n=3445)\end{array}$ & \\
\hline Year of $\mathrm{OHCA}$ & & & & 0.01 \\
\hline 2011 & 2287-19.1 & $1620-19.0$ & $667-19.4$ & \\
\hline 2012 & $2263-18.9$ & $1640-19.3$ & $623-18.1$ & \\
\hline 2013 & $2432-20.3$ & $1696-19.9$ & $736-21.4$ & \\
\hline 2014 & $2391-20.0$ & 1675-19.7 & 716-20.8 & \\
\hline 2015 & $2582-21.6$ & $1879-22.1$ & $703-20.4$ & \\
\hline OHCA during daytime 08:00 - 20:00 (643/293)* & $7275-66.0$ & $5363-68.2$ & $1912-60.7$ & 0.16 \\
\hline Age (years) & $72(52,87)$ & $71(50,87)$ & $75(55,88)$ & 0.27 \\
\hline Female sex & $3778-31.6$ & $2615-30.7$ & $1163-33.8$ & 0.06 \\
\hline VF/VT as first monitored rhythm (337/91) & $3456-30.0$ & $2784-34.1$ & $672-20.0$ & 0.32 \\
\hline OHCA at home $(5 / 2)$ & $8430-70.6$ & $5637-66.3$ & $2793-81.1$ & 0.34 \\
\hline Mechanical chest compression(581/293) & $4188-37.8$ & $2993-37.7$ & $1195-37.9$ & 0.00 \\
\hline Cardiac aetiology (408/142) & $8070-70.8$ & $5759-71.1$ & $2311-70.0$ & 0.02 \\
\hline \multicolumn{5}{|l|}{ Treatment } \\
\hline Adrenalin (103/39) & $9813-83.1$ & $6862-81.6$ & $2951-86.6$ & 0.14 \\
\hline Intubation (70/32) & $4345-36.7$ & $3125-37.0$ & $1220-35.7$ & 0.03 \\
\hline Anti-arrythmics (196/86) & $1893-16.2$ & $1440-17.3$ & $453-13.5$ & 0.11 \\
\hline \multicolumn{5}{|l|}{ Delay (minutes) } \\
\hline Collapse to start of CPR (950/496) & $4(0,16)$ & $2(0,12)$ & $10(2,20)$ & 1.23 \\
\hline Call for EMS to EMS arrival (1426/626) & $10(4,21)$ & $10(4,22)$ & $8(4,17)$ & 0.35 \\
\hline
\end{tabular}

Results presented as number (\%) or median (10th, 90th percentile)

*Number of patients with missing information of those receiving and not receiving bystander CPR, respectively.

†Standardised difference between the two groups

CPR, cardiopulmonary resuscitation; EMS, emergency medical services; ROSC, return of spontaneous circulation; VF/VT, ventricular fibrillation/ventricular tachycardia. 
rhythm). However, adjustment also for initial rhythm is presented in online supplementary table 1 . To assess the possible effect of comorbidity on outcomes, we compared ORs for bystander CPR (in relation to no bystander CPR) in models not involving CCI with the models where CCI was included. To analyse possible interactions between bystander CPR and CCI, the model without the interaction term was compared with the model with this term included. For descriptive purposes, we divided patients according to CCI intervals and produced interval-specific forest plots for each of the four outcome analyses.

Due to the amount of missing data regarding one or more of the adjustment factors (21\% of the patients), we used multiple imputations for the multivariable analysis. Missing data were assumed to be missing at random and 50 imputed data sets were generated with the Markov chain Monte Carlo method using the expectation-maximisation algorithm. Rubin's rules were used for pooling of the results from the imputed data sets. Outcome endpoints were not imputed, and thus only patients for whom 30-day survival status and whether ROSC occurred were known were included in the respective analysis. The procedure above was repeated separately for each outcome analysis and for the subgroups of patients with ventricular fibrillation/ventricular tachycardia (VF/VT) and patients with non-shockable rhythm as the initial rhythm. For comparative purposes, we also performed a complete case analysis (ie, only using patients with no missing on the adjustment factors) (online supplementary table 2).

Tests were two sided and $\mathrm{p}$ values $<0.05$ were considered statistically significant. All analyses were performed using SAS software V.9.4 for Windows.

\section{RESULTS}

Altogether, 25540 OHCA cases were registered in the SRCR during the study period (2011-2015). After exclusion of cases as presented in figure 1, 11955 cases with witnessed OHCA were included in the study.

\section{Characteristics of the patients}

Bystander CPR was performed in 8510 cases (71\%). Patients who received bystander CPR were younger on average, a higher proportion presented with VF/VT as first monitored rhythm, a lower proportion of their collapses had occurred at home and there was a slightly lower proportion of women.

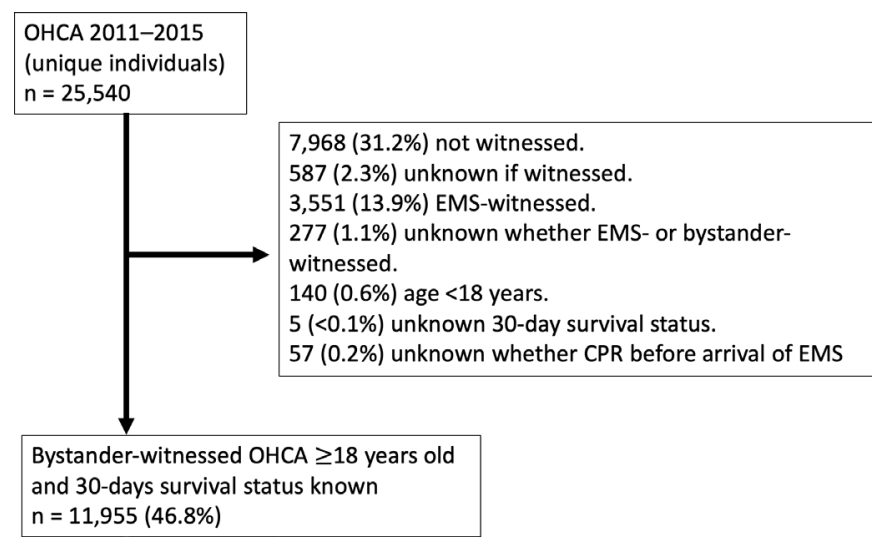

Figure 1 Flowchart of patient selection for the study.
Table 2 Outcome in relation to whether bystander CPR was performed before the arrival of EMS or not.

\begin{tabular}{|c|c|c|c|c|}
\hline & & $\begin{array}{l}\text { Bystander } \\
\text { CPR }\end{array}$ & & \\
\hline & $\begin{array}{l}\text { All patients } \\
(n=11955)\end{array}$ & $\begin{array}{l}\text { Yes } \\
(n=8510)\end{array}$ & $\begin{array}{l}\text { No } \\
(n=3445)\end{array}$ & $p$ value \\
\hline \multicolumn{5}{|l|}{$\begin{array}{l}\text { Survival at } \\
30 \text { days }\end{array}$} \\
\hline All patients & $1592-13.3$ & $1361-16.0$ & $231-6.7$ & $<0.0001$ \\
\hline $\begin{array}{l}\text { Patients with } \\
\text { VF/VT as first } \\
\text { monitored rhythm }\end{array}$ & $1093-31.6$ & $953-34.2$ & $140-20.8$ & $<0.0001$ \\
\hline $\begin{array}{l}\text { Patients with } \\
\text { other initial } \\
\text { arrhythmia }\end{array}$ & $338-4.2$ & $254-4.7$ & $84-3.1$ & 0.0008 \\
\hline $\begin{array}{l}\text { ROSC anytime } \\
(210 / 129)^{*}\end{array}$ & 4597-39.6 & $3396-40.9$ & $1201-36.2$ & $<0.0001$ \\
\hline $\begin{array}{l}\text { ROSC at arrival } \\
\text { in hospital } \\
(179 / 74)\end{array}$ & $3676-31.4$ & 2759-33.1 & $917-27.2$ & $<0.0001$ \\
\hline $\begin{array}{l}\text { Results presented } \\
{ }^{*} \text { Number of patien } \\
\text { bystander CPR, res } \\
\text { CPR, cardiopulmon } \\
\text { of-hospital cardiac }\end{array}$ & $\begin{array}{l}\text { as number (\%) } \\
\text { ts with missing } \\
\text { pecitvely. } \\
\text { ary resuscitatior } \\
\text { arrest; VF/VT, ve }\end{array}$ & $\begin{array}{l}\text { rmation of } \\
\text { AS, emerge } \\
\text { cular fibrill }\end{array}$ & $\begin{array}{l}\text { receiving ar } \\
\text { edical servic } \\
\text { ventricular t }\end{array}$ & $\begin{array}{l}\text { ot receiving } \\
\text { Cardia. }\end{array}$ \\
\hline
\end{tabular}

The median time from collapse to start of CPR was substantially shorter in patients who received bystander CPR than in patients who did not $(2 \mathrm{~min}$ vs $10 \mathrm{~min})$, but a longer time elapsed between the emergency call and the arrival of EMS (10 $\mathrm{min}$ vs $8 \mathrm{~min})$ (table 1$)$.

The survival at 30 days was $16.0 \%$ when bystander CPR was started, as compared with $6.7 \%$ when CPR was not started before the arrival of EMS $(\mathrm{p}<0.0001)$. Patients who received bystander CPR received ROSC at any time and also on arrival at hospital more frequently than patients who did not $(40.9 \%$ vs $36.2 \%$ and $33.1 \%$ vs $27.2 \%$, respectively; $\mathrm{p}<0.0001$ for both comparisons) (table 2).

\section{Comorbidity of the patients}

According to CCI, the degree of comorbidity was slightly lower in those who received bystander CPR (for details see table 3 and figure 2) (mean \pm SD: $2.2 \pm 2.3$ vs $2.5 \pm 2.4 ; \mathrm{p}<0.0001)$. Of those who received bystander CPR, 29.6\% had a CCI value of 0 (ie, no comorbidity at all), as opposed to $24.9 \%$ for those who did not receive CPR (figure 2).

\section{Association of bystander CPR and 30-day survival}

After adjusting for age, sex, location, aetiology and time delay between the emergency call and arrival of EMS, the OR regarding 30-day survival was 2.34 (95\% CI 2.01 to 2.74) for patients who received bystander CPR in relation to those who did not. Adding CCI to the model did not imply any major change in this ratio (OR 2.32, 95\% CI 1.98 to 2.71) (figure 3). The degree of association between bystander CPR and 30-day survival did not change with the severity of comorbidity $(p=0.61$ for interaction between bystander CPR and CCI, for details see figure 4). Repeating these analyses including initial rhythm as an additional covariate in the model resulted in a weaker association between bystander CPR and survival, but still almost identical regardless whether adjusted for CCI or not (online supplementary file 1). When using only complete cases we found no major differences from the results above using multiple imputation (online supplementary table 2). 
Table 3 Comorbidity in relation to whether bystander CPR was performed before the arrival of EMS or not.

\begin{tabular}{|c|c|c|c|c|c|}
\hline & & Bystander CPR & & & \\
\hline & $\begin{array}{l}\text { All patients } \\
(\mathrm{n}=11955)\end{array}$ & $\begin{array}{l}\text { Yes } \\
(n=8510)\end{array}$ & $\begin{array}{l}\text { No } \\
(n=3445)\end{array}$ & $P$ value & $\begin{array}{l}\text { Standardised } \\
\text { difference* }\end{array}$ \\
\hline \multicolumn{6}{|l|}{ Comorbidity within 5 years before $\mathrm{OHCA}$} \\
\hline Myocardial infarction & $2915(24.4)$ & $2040(24.0)$ & $875(25.4)$ & 0.10 & 0.03 \\
\hline Congestive heart failure & $3441(28.9)$ & $2350(27.6)$ & $1091(31.7)$ & $<0.0001$ & 0.09 \\
\hline Peripheral vascular disease & $1356(11.3)$ & $925(10.9)$ & $431(12.5)$ & 0.01 & 0.05 \\
\hline Chronic pulmonary disease & $2240(18.7)$ & $1495(17.6)$ & $745(21.6)$ & $<0.0001$ & 0.10 \\
\hline Connective tissue disorder/rheumatic disease & $650(5.4)$ & $455(5.3)$ & $195(5.7)$ & 0.50 & 0.01 \\
\hline Peptic ulcer disease & $355(3.0)$ & $237(2.8)$ & $118(3.4)$ & 0.07 & 0.04 \\
\hline Mild liver disease & $344(2.9)$ & $243(2.9)$ & $101(2.9)$ & 0.81 & 0.00 \\
\hline Diabetes without complications & $2715(22.7)$ & $1857(21.8)$ & $858(24.9)$ & 0.0003 & 0.07 \\
\hline Metastatic carcinoma & $525(4.4)$ & $352(4.1)$ & $173(5.0)$ & 0.03 & 0.04 \\
\hline Moderate or severe liver disease & $71(0.6)$ & $37(0.4)$ & $34(1.0)$ & 0.0009 & 0.07 \\
\hline AIDS/HIV & $10(0.1)$ & $5(0.1)$ & $5(0.1)$ & 0.16 & 0.03 \\
\hline \multicolumn{6}{|l|}{ Charlson Comorbidity Index (CCI) } \\
\hline Points & $2(0,6)$ & $2(0,6)$ & $2(0,6)$ & $<0.0001$ & 0.14 \\
\hline Mean \pm SD & $2.3 \pm 2.4$ & $2.2 \pm 2.3$ & $2.5 \pm 2.4$ & & \\
\hline
\end{tabular}

Results presented as number (\%) or median (10th, 90th percentiles), unless otherwise stated.

*Standardised difference between the two groups.

CPR, cardiopulmonary resuscitation; EMS, emergency medical services; OHCA, out-of-hospital cardiac arrest.

\section{Patients with shockable or non-shockable first monitored rhythm}

The adjusted OR for CPR before the arrival of EMS in relation to no bystander CPR regarding 30-day survival in patients with VF/VT as the first monitored rhythm was 1.94 (95\% CI 1.55 to 2.42). When also adjusting for CCI, the OR was again almost identical $(1.93,95 \%$ CI 1.55 to 2.41$)$. A similar absence of CCI effect was found in patients with non-shockable first monitored rhythm (although the overall association between bystander CPR and survival was weaker in this subgroup) (figure 3). The interaction between bystander CPR and CCI

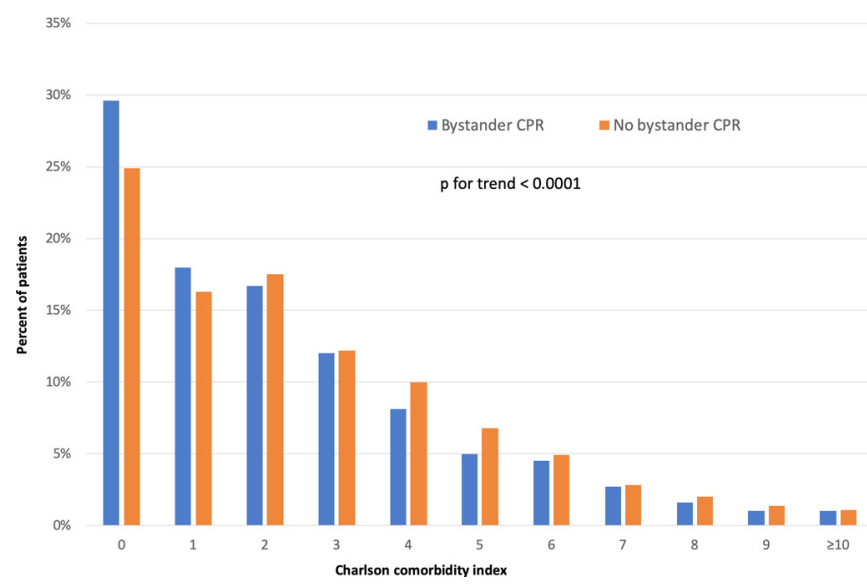

Figure 2 Charlson comorbidity index among those who received bystander CPR before the arrival of EMS or not. Patients who received bystander CPR had somewhat lower number of total CCI points compared to those who did not. regarding 30-day survival did not reach statistical significance in patients neither with non-shockable nor shockable first monitored rhythm ( $p=0.052$ and $p=0.16$, respectively). (figure 4).

\section{Association between bystander CPR and ROSC}

The adjusted ORs for bystander CPR in relation to no bystander CPR regarding ROSC at any time and ROSC at hospital admission were 1.29 (95\% CI 1.18 to 1.41 ) and 1.38 (95\% CI 1.25 to 1.51 ), respectively. Although similar associations were found regardless of whether adjusting for CCI or not, there were significant interactions between bystander CPR and the degree of comorbidity regarding both ROSC at any time and at hospital admission, with a decreasing effect of bystander CPR with increasing degree of comorbidity (figure 4).

\section{DISCUSSION}

The major finding in this nationwide study was that the positive effect of bystander CPR on 30-day survival was not confounded by previous comorbidities. Although patients who received bystander CPR had somewhat less comorbidities than patients who did not receive such treatment, the association between bystander CPR and 30-day survival was unaffected after adjustment for the degree of comorbidity. However, with regard to ROSC at any time and ROSC at hospital admission, the effect of bystander CPR was associated with the degree of comorbidity, in that the effect of bystander CPR diminished with increasing severity of comorbidity.

Giving CPR is recommended by international guidelines on early response in cardiac arrest. ${ }^{21} \mathrm{~A}$ number of studies have shown an association between bystander CPR and survival after 


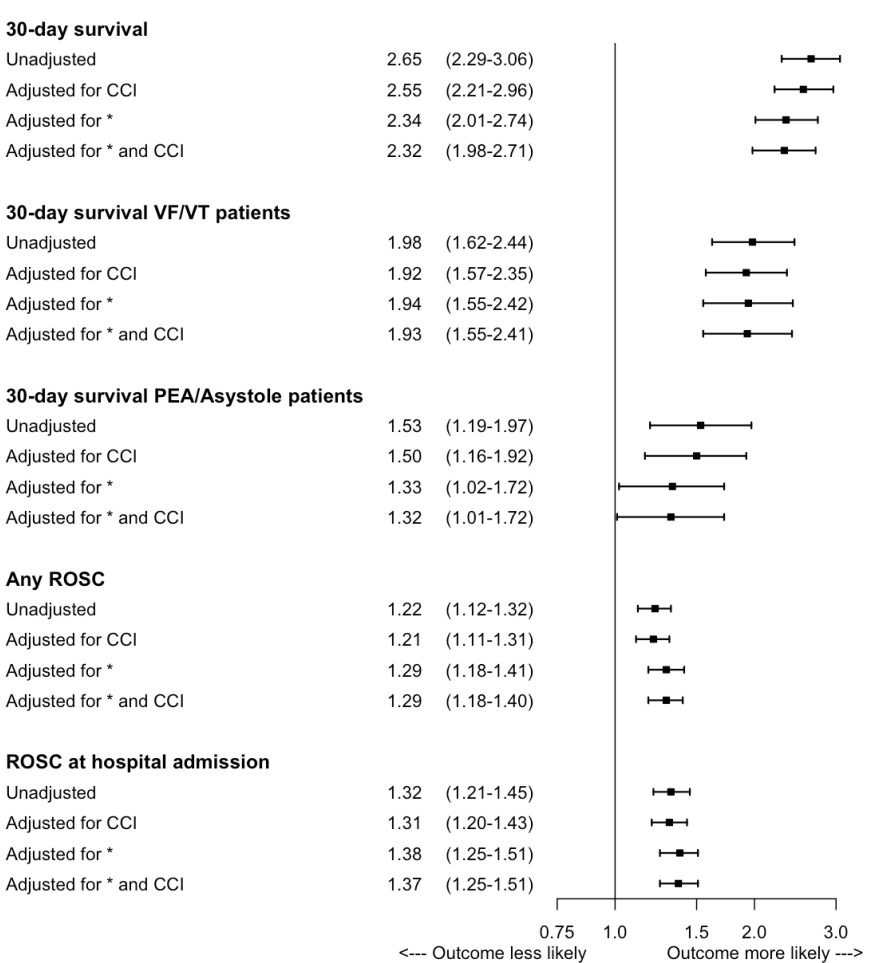

Figure 3 Unadjusted and adjusted odds ratio regarding the three outcomes. *Age, sex, location, etiology, and time from call to EMS to EMS arrival. OR $95 \% \mathrm{Cl}$, odds ratio and corresponding 95\% confidence interval for those receiving bystander CPR in relation to those not receiving bystander $\mathrm{CPR}$. $\mathrm{CCl}$, Charlson comorbidty index. PEA, pulseless electrical activity. ROSC, return of spontaneous circulation.

OHCA, ${ }^{4} 22$ and the results of our study further support these findings.

The evidence for the recommendation of giving CPR before arrival of EMS is based on studies with registry data. No single trial has ever been performed whereby patients were randomised to (1) CPR before arrival of EMS or (2) no CPR before arrival of EMS. For ethical reasons, no such trial will most likely ever be performed. We therefore must analyse registry data in the most optimal way. The critical issue is to include all relevant confounders in the analysis and to be convinced that there are no hidden confounders that have not been considered, the latter being of course impossible to prove. One example of a possible confounder that has been hidden for years in most studies that have evaluated the effect of bystander CPR after OHCA is comorbidity. Our findings suggest that the degree of comorbidity is not a confounder regarding the positive association between bystander CPR and 30-day survival. However, the degree of comorbidity appears to influence the association between bystander CPR and the chance of ROSC both at any time and at hospital admission, with a stronger effect of bystander CPR in those patients with less severe comorbidity. Possible explanations as to how the degree of comorbidity appears to influence the association between bystander CPR and ROSC could be mediated through shockable rhythm. We determined in a previous study ${ }^{13}$ that the proportion of patients found in VF/VT decreased with increasing comorbidity.

Our results support the idea that CPR given before the arrival of EMS is effective and should be recommended regardless of

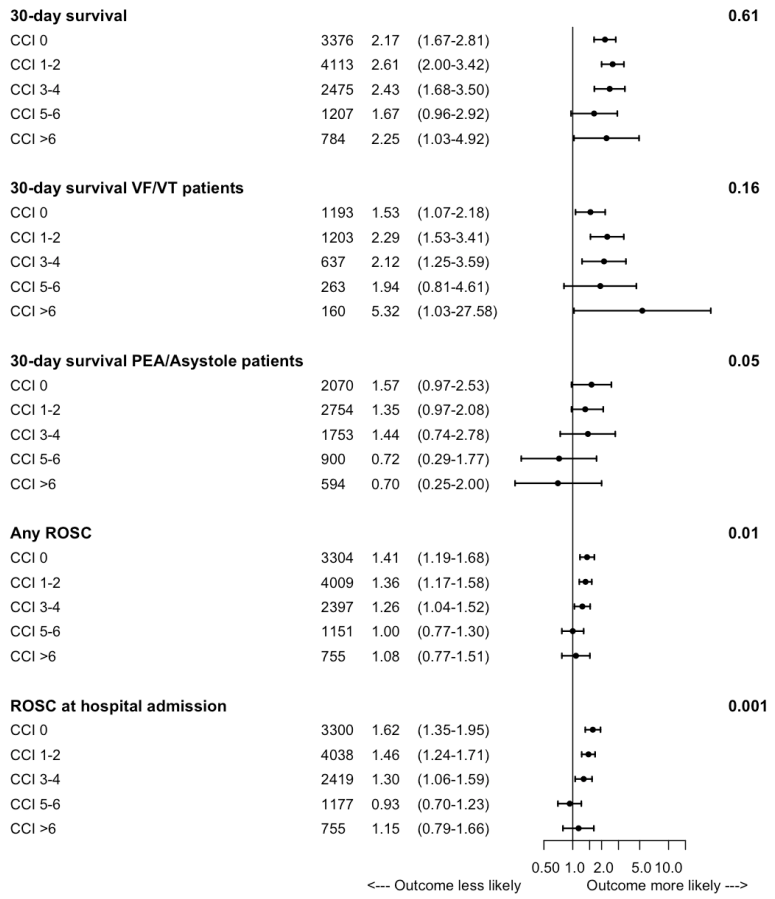

Figure $4 \mathrm{CCl}$ interval specific adjusted* ${ }^{*}$ odds ratios regarding the three outcomes. *Adjusted for age, sex, location, etiology, and time from call to EMS to EMS arrival. \# p-value for interaction between bystander CPR yes/no and CCI regarding outcome (acutal CCI value used in p-value calculation). OR 95\% Cl: odds ratio and corresponding $95 \%$ confidence interval for those receiving bystander CPR in relation to those not receiving bystander $\mathrm{CPR}$. $\mathrm{CCl}$, Charlson comorbidity index. PEA, pulseless electrical activity. ROSC, return of spontaneous circulation.

comorbidity, since there was no interaction between bystander $\mathrm{CPR}$ and comorbidity regarding survival. Having said that, one certainly must consider other contraindications to start of CPR ('do not attempt resuscitation' issues, and so on). To our knowledge, no previous study has addressed the question of whether coexisting illnesses might affect the association between bystander CPR and survival after OHCA. We have previously reported that CPR before the arrival of EMS is performed less frequently in patients with higher degree of comorbidity. ${ }^{13}$ One might consider that frail patients with several comorbidities would be less likely to receive bystander CPR, as a bystander might be reluctant to initiate CPR on such a patient. Our results suggest that bystander CPR before the arrival of EMS is performed in younger and more healthier patients.

The finding that patients who collapse outside their home are more likely to receive bystander CPR is consistent with findings in other studies. ${ }^{2324}$ It is more likely that those witnessing the cardiac arrest in public have had a CPR training and are therefore more likely to start CPR.

In addition, we found that patients who received bystander CPR were more frequently found in a shockable rhythm. This is in agreement with previous findings. ${ }^{425}$ It has been suggested that one of the mechanisms behind the association between bystander CPR and increased survival is maintenance of $\mathrm{VF} /$ VT due to enhanced coronary perfusion. ${ }^{89}$ Thus, the effect of bystander CPR could be in prolonging the shockable phase of 
$\mathrm{VF} / \mathrm{VT}$. This is why we did not adjust for the difference in first monitored rhythm in our primary analyses.

We limited our analysis to witnessed OHCA cases only. The reason for this was to minimise the number of patients who had a very small chance of survival, and when the time of the cardiac arrest is unknown other factors become more important-such as delay in initiating treatment.

In this study, apart from the year 2015, we lacked information on the proportion of patients who had CPR started by a witness. Although we assume that the vast majority of patients who received CPR before the arrival of EMS had 'true bystander CPR', we know that in a number of cases CPR was started by other dispatched units (firefighters or police, during 2015 it was $2 \%)$. In this way, there is some confusion about the definition of bystander CPR, which has recently been brought to light. ${ }^{26}$

In summary, we have found that patients with witnessed OHCA who underwent bystander CPR were slightly healthier than those who did not undergo bystander CPR, and that the positive effect of bystander CPR on 30-day survival was not affected by patient comorbidity. This supports previous evidence that bystander CPR is an effective and important link in the chain of survival and increases the chance of 30-day survival regardless of patient comorbidity.

\section{Strengths and limitations}

The strengths of the present study were as follows. First, we used a large nationwide SRCR registry that prospectively collects data on OHCA in Sweden, with large cohorts. Second, the data on previous comorbidities were obtained from the comprehensive NPR registry, which covers all outpatient and inpatient care since 2001. We used multiple imputation technique to handle the problem of potential bias when including only complete data.

There were also several limitations. First, we only had data on comorbidity diagnosis from 5 years before the OHCA. In the NPR, the diagnoses do not take account of the grade and duration of the disease. We were unable to adjust for that healthier patients are more likely to receive more resuscitation effort, as well as inhospital factors and treatment such as hypothermia and coronary interventions in the postresuscitation phase. The study was conducted in Sweden, and there are uncertainties whether our results can be generalised to other parts of the world, as

\section{Key questions}

\section{What is already known on this subject?}

- Bystander cardiopulmonary resuscitation (CPR) before the arrival of emergency medical services (EMS) is a vital link in the chain of survival and increases survival after cardiac arrest. Patients' comorbidities may have a possible influence on the effect that bystander CPR has on survival.

\section{What might this study add?}

- This study widens our knowledge regarding comorbidities in patients who have undergone CPR before the arrival of EMS.

- Our study highlights the importance of bystander CPR, and shows that the positive effect of bystander CPR on survival is not affected by the degree of comorbidity of the patient.

\section{How might this impact on clinical practice?}

- Giving bystander CPR before the arrival of EMS can have a positive effect irrespective of the severity of comorbidity. It can be beneficial in cardiac arrest. cultural and other psychosocial factors may play a role in the initiation of bystander CPR.

\section{CONCLUSION}

Patients who received CPR before the arrival of EMS had a somewhat lower degree of comorbidity than those who did not. When taking this difference into account, bystander CPR was still associated with a marked increase in 30-day survival after OHCA.

Contributors Each author has contributed significantly to the submitted work, in terms of design of study, data acquisition, analysis or interpretation, drafting the article or revising it and final approval of the manuscript.

Funding The study was supported by the Swedish state under the ALF agreement (ALFGBG 716901).

Competing interests None declared.

Patient consent for publication Not required.

Provenance and peer review Not commissioned; externally peer reviewed.

Data availability statement Data are available upon reasonable request.

Open access This is an open access article distributed in accordance with the Creative Commons Attribution Non Commercial (CC BY-NC 4.0) license, which permits others to distribute, remix, adapt, build upon this work non-commercially, and license their derivative works on different terms, provided the original work is properly cited, appropriate credit is given, any changes made indicated, and the use is non-commercial. See: http://creativecommons.org/licenses/by-nc/4.0/.

\section{ORCID iDs}

Geir Hirlekar http://orcid.org/0000-0002-0970-8633

Martin Jonsson http://orcid.org/0000-0002-3539-8317

\section{REFERENCES}

1 Berdowski J, Berg RA, Tijssen JGP, et al. Global incidences of out-of-hospital cardiac arrest and survival rates: systematic review of 67 prospective studies. Resuscitation 2010;81:1479-87.

2 Gräsner J-T, Lefering R, Koster RW, et al. EuReCa ONE-27 nations, one Europe, one registry: a prospective one month analysis of out-of-hospital cardiac arrest outcomes in 27 countries in Europe. Resuscitation 2016;105:188-95.

3 Holmberg M, Holmberg S, Herlitz J. Incidence, duration and survival of ventricular fibrillation in out-of-hospital cardiac arrest patients in Sweden. Resuscitation 2000:44:7-17.

4 Hasselqvist-Ax I, Riva G, Herlitz J, et al. Early cardiopulmonary resuscitation in out-ofhospital cardiac arrest. N Engl J Med 2015;372:2307-15.

5 Sasson C, Rogers MAM, Dahl J, et al. Predictors of survival from out-of-hospital cardiac arrest: a systematic review and meta-analysis. Circ Cardiovasc Qual Outcomes 2010;3:63-81

6 Holmberg M, Holmberg S, Herlitz J, et al. Survival after cardiac arrest outside hospital in Sweden. Resuscitation 1998;36:29-36.

7 Herlitz J, Ekstrom L, Wennerblom B, et al. Effect of bystander initiated cardiopulmonary resuscitation on ventricular fibrillation and survival after witnessed cardiac arrest outside Hospital. Heart 1994;72:408-12.

8 Eftestøl T, Wik L, Sunde K, et al. Effects of cardiopulmonary resuscitation on predictors of ventricular fibrillation defibrillation success during out-of-hospital cardiac arrest. Circulation 2004:110:10-15

9 Waalewijn RA, Nijpels MA, Tijssen JG, et al. Prevention of deterioration of ventricular fibrillation by basic life support during out-of-hospital cardiac arrest. Resuscitation 2002;54:31-6

10 Fouche PF, Carlson JN, Ghosh A, et al. Frequency of adjustment with comorbidity and illness severity scores and indices in cardiac arrest research. Resuscitation 2017;110:56-73.

11 Søholm H, Hassager C, Lippert F, et al. Factors associated with successful resuscitation after out-of-hospital cardiac arrest and temporal trends in survival and comorbidity. Ann Emerg Med 2015;65:523-31.

12 Andrew E, Nehme Z, Bernard S, et al. The influence of comorbidity on survival and long-term outcomes after out-of-hospital cardiac arrest. Resuscitation 2017; 110:42-7.

13 Hirlekar G, Jonsson M, Karlsson T, et al. Comorbidity and survival in out-of-hospital cardiac arrest. Resuscitation 2018;133:118-23.

14 Statistics Sweden. Statistikdatabasen, 2019. Available: http://www.statistikdatabasen. scb.se/ [Accessed 8. augusti 2019].

15 Perkins GD, Jacobs IG, Nadkarni VM, et al. Cardiac arrest and cardiopulmonary resuscitation outcome reports: update of the Utstein resuscitation registry templates for out-of-hospital cardiac arrest. Resuscitation 2015;96:328-40. 
16 Strömsöe A, Svensson L, Axelsson Å.B., et al. Validity of reported data in the Swedish cardiac arrest register in selected parts in Sweden. Resuscitation 2013;84:952-6.

17 Ludvigsson JF, Andersson E, Ekbom A, et al. External review and validation of the Swedish national inpatient register. BMC Public Health 2011;11:450.

18 Quan H, Sundararajan V, Halfon P, et al. Coding algorithms for defining comorbidities in ICD-9-CM and ICD-10 administrative data. Med Care 2005:43:1130-9.

19 Hirlekar G, Jonsson M, Karlsson T, et al. Analysis of data for comorbidity and survival in out-of-hospital cardiac arrest. Data in Brief 2018;21:1541-51.

20 Austin PC. Using the standardized difference to compare the prevalence of a binary variable between two groups in observational research. Commun Stat Simul Comput 2009;38:1228-34.

21 Perkins GD, Handley AJ, Koster RW, et al. European resuscitation Council guidelines for resuscitation 2015. section 2. adult basic life support and automated external defibrillation. Resuscitation 2015;95:81-99.
22 Wissenberg M, Lippert FK, Folke F, et al. Association of national initiatives to improve cardiac arrest management with rates of bystander intervention and patient survival after out-of-hospital cardiac arrest. JAMA 2013:310:1377-84.

23 Herlitz J, Eek M, Holmberg M. Characteristics and outcome among patients having out of hospital cardiac arrest at home compared with elsewhere. Heart 2002;88:579-82.

24 Swor RA, Jackson RE, Compton S, et al. Cardiac arrest in private locations: different strategies are needed to improve outcome. Resuscitation 2003;58:171-6.

25 Holmberg M, Holmberg S, Herlitz J. Factors modifying the effect of bystander cardiopulmonary resuscitation on survival in out-of-hospital cardiac arrest patients in Sweden. Eur Heart J 2001;22:511-9.

26 Maurer $\mathrm{H}$, Masterson S, Tjelmeland IB, et al. When is a bystander not a bystander any more? a European survey. Resuscitation 2019;136:78-84. 